\title{
Considerations on the Stability Analysis of Subterranean Mining Sites in the Sasar Mining Area- Romania Using Topographical Methods for a Future Re-usage
}

\author{
Ovidiu Stefan \\ Technical University Cluj-Napoca - North University Center of Baia Mare, Baia Mare, 430083, Romania \\ o.stefan@ymail.com
}

\begin{abstract}
If the subterranean mining sites are expected to be re-used, determining their stability is fundamental for defining the type of application that will be used. This paper presents general considerations concerning the movement of the rocks in the subterranean mining sites and the topographical measurements used for determining the stability of subterranean mining sites of Sasar mine-Romania, for their future re-usage.

Index Terms - influence area, topographical measurements, stability, usage.
\end{abstract}

\section{I . Introduction}

Your goal is to simulate the usual appearance of papers in Sasar mining site is situated in the north-western part of Baia Mare municipality, with a total surface of approx. $25 \mathrm{sq} \mathrm{km}$ that stretches south from Sasar River, towards north to Ulmoasa commune and hill, Firiza River to east and Baita River to vest ${ }^{1}$.

In the mining area of Sasar, according to the geological description, there can be found two types of mineralization:

- an auriferous type that presents the majority of its useful minerals in quartz gangue (Sofia, Valea Rosie, Dealul Crucii ores - the superior part) or in andesite breccias (Borzas ore) ${ }^{4}$;

- a complex poly-metallic type that presents its mineralization in quartz and calcite gangues (Dealul Crucii ore- the inferior part) ${ }^{5,10}$.

\section{General considerations in the field of mining}

The stability of the rocks from the ceiling and shelf of the veins is, generally speaking, in a functional state ${ }^{2}$. From the point of view of its strengthens, the sterile mass together with the ore can be labeled as being of category II and III, with a strengthen indicator $\mathrm{f}=6-12$.

In Sasar mining area, the evolution of the exploitation methods over the time, has been influenced by the existing geo-mining conditions, the physical- mechanical properties of the ore and the surrounding rocks, by the development of the equipments and logistics, the used explosives, aspects concerning the shortage of used materials (wood, metal, cement), the preparation technologies, several economical conditions and last but not least, requirements concerning the safety of works and of the exploited ore.

\section{General aspects concerning the movement of the rocks in the subterranean cavities}

By exploiting the subterranean ores, different subterranean mining spaces (called technological cavities) are created, generating a disturbance in the initial existent balance of the massifs. Under the influence of litho-statically pressure and the gravity force, the surrounding rocks are deformed and start to migrate towards the interior of the excavated space ${ }^{7}$. As a result, there is the possibility of caving the walls and the ceiling of these empty spaces, along the parts of the massif that have been weakened by the coarse crevice by tectonic disturbances, that destroyed the mining works located in the influence area of the cavities and sometimes by the occasional movements in the earth's surface ${ }^{4,5}$.

If the resistance of the surrounding rocks is stronger than the acting charges, the fall doesn't take place and the formed cavities preserve a certain state of stability.

If this stability doesn't exist and the fall takes place, as a consequence of the differentiated amplitude of the movement of the rocks, three types of influence areas can be identified along the subterranean technological cavities (fig. 1):

- III degree influence area or falling area, situated in the area next to the cavity;

- II degree influence area, the area of the crevices and intense movements;

- I degree influence area, or the area of the reduced movements.

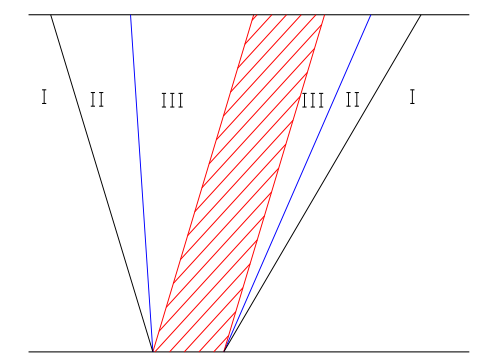

Fig. 1 The types of influence areas can be identified along the subterranean technological cavities 
In order to reduce the expansion and the effects of these influence areas, certain measures can be taken:

- reducing the volume of the technological cavities by total or partial stowing;

- preserving some pillars in the direction of the ore, reducing the direction of the expansion of the cavity;

- reducing the thickness of the exploited bodies;

- reducing the expansion of the cavities on height.

The indicators used for quantified description and estimation of the movement process under different geological and mining conditions and for the determining of the safety pillars $^{12}$ are also the parameters of the movement process:

- break angle, movement angle and limit (in the ceiling, floor and direction);

- the limit depth ${ }^{6}$;

- the limit expansion of the crevices;

- undermining depth.

Revealing the movement parameters of the rocks is very important as it influences the determination of:

- safety pillars of the mining constructions both on the surface and subterranean;

- choosing the exploitation method;

- the disposal and speed of some pieces and parts from the ore;

- the setting of some mining works in the subterranean or surface;

- providing the safety of the ore deposit;

- future possibilities of using the subterranean spaces

In order to predict the parameters of the rocks movement and the stability of the subterranean spaces it is necessary to acknowledge the factors determining these parameters.

\section{Factors that influence the stability of the subterranean mining spaces}

The factors that influence the stability of the subterranean mining spaces and the evolution of the movement of surrounding rocks are the followings:

(1) Natural factors related to the ore:

- the shape of the ore (veined, lensing, etc.);

- the distance between the ore and the surface;

- the thickness of the ore;

- the leaning of the ore;

- the physical-mechanical properties of the ore and their life-span variations;

- the nature of the contact between the ore and the surrounding rocks;

(2) Natural factors related to the surrounding rocks:

- the physical-mechanical properties of the surrounding rocks their life-span variations;

- the presence and the orientation of the minimal resistance planes (faults, contact planes, crevices, etc.);

- the natural fissuring degree of the surrounding rocks formations;
- the elementary alteration degree;

- hydro-geological conditions.

(3) Factors related to the exploitation activity:

- the dimensions of the formed cavity;

- the used exploitation method;

- the direction in the exploitation of the ore;

- the technologies used for removing the rocks.

V. Topographical measurements for determining the stability of the subterranean mining sites

\section{A. Technical Considerations}

Subterranean mining sites can be created by excavating different types of mining works like opening, preparing, and special ones or can be created by executing mining works to avoid the useful mineral substances. In this case, different exploitation methods are used and represent the largest volume of the entire cavities.

As a consequence, the works conducted for verifying the stability of the subterranean mining sites had two directions:

- stabilizing the subterranean mining sites that were the result of opening, preparing and special mining works;

- stabilizing the subterranean mining sites that were the result of the deviation of the useful mineral substances.

The necessity of conducting measurements and their setting up is determined by some modifications in the pressure status, like the followings:

- the appearance and evolution of some cracks and crevices ${ }^{3}$;

- shrinking the profile of the mining works due to the swelling of the floor or due to the exaggeration of convergents;

- deformation of the sustaining elements.

After establishing the type of the mining works and the necessary topographical measurements ${ }^{9}$, it is necessary to carry out some preparatory works like:

- establishing the stable topographical points (groups of strong points) and the landmarks from the known level (elevation) that will later contribute to the setting up of the reference system;

- choosing the type of landmarks used for each work and the type of measurements that will be executed;

- setting the landmarks at the established sites;

- marking the measurement sites on the topographical plans.

\section{$B$. Establishing the range of topographical measurements}

As the phenomenon of the stability of mining sites is strongly connected with the time factor, especially with the age of the cavities that can be either galleries or adits, the measurements were oriented to comprise a variety of situations.

The main technique used for assessing the stability of the subterranean mining sites was the middle geometric leveling of the ceiling and floor of the horizontal mining works, a technique that was combined with detailed methods in the 
cases where a profound analysis of the phenomenon was necessary. Likewise, in the case of the elementary crevices that are in an initial phases, the same process is carried out in order to timely acknowledge the evolution of the phenomenon using 2 millimeter glass markers set in established places on those crevices.

In order to apply the chosen monitoring method - the geometric leveling of the ceiling and floor of the horizontal mining works, after having covered the preparatory stages presented above and determining the leveling markers set in the stable points, it was necessary was to set up the landmarks as a basis for future measurements. These marks were set up in the ceiling and floor of the mining works, especially chosen for monitoring at a distance of 3 meters from each other.

In the case of detailed methods applied for the determination of the mining works' profile, the process of location consisted of setting up a topographical point in the ceiling or floor of the mining works that later became the stable point for all measurements carried out during the time in that particular area. Also, the process comprised the setting up of several markers at different distances and angles on the perimeter of the mining work in a transversal plan to the axis of the mining work. The process of location was made up of markers used to materialize the topographical points, of paint marks, metal pieces, hooks and other objects available at the site of works.

The measurements were taken for a period of 7 years, the frequency set was taken into consideration on-site conditions, but as a general rule, measurements were made on quarterly basis.

The topographical measurements implied the execution of some middle geometric leveling ${ }^{13}$ subsidence of the ceiling and floor of the mining works with closure on the starting point or on a point with a known level in order to compensate the levels, to obtain an appropriate precision.

Level measurements were conducted with an Japanese production instrument - Sokkia - TTL.

\section{$C$. Interpreting the measurements and selecting the location of the measurements}

The mining works where the topographical measurements were taken in order to determine the stability of the subterranean mining sites, were carefully chosen so that the main typical areas of the ore would be comprised and to on site verify the expansion of the analytic influence areas .

After calculating the level compensation, several graphics resulted, representing on scale longitudinal profiles of the assed mining works on which the markers were materialized by using their level (fig. 2).
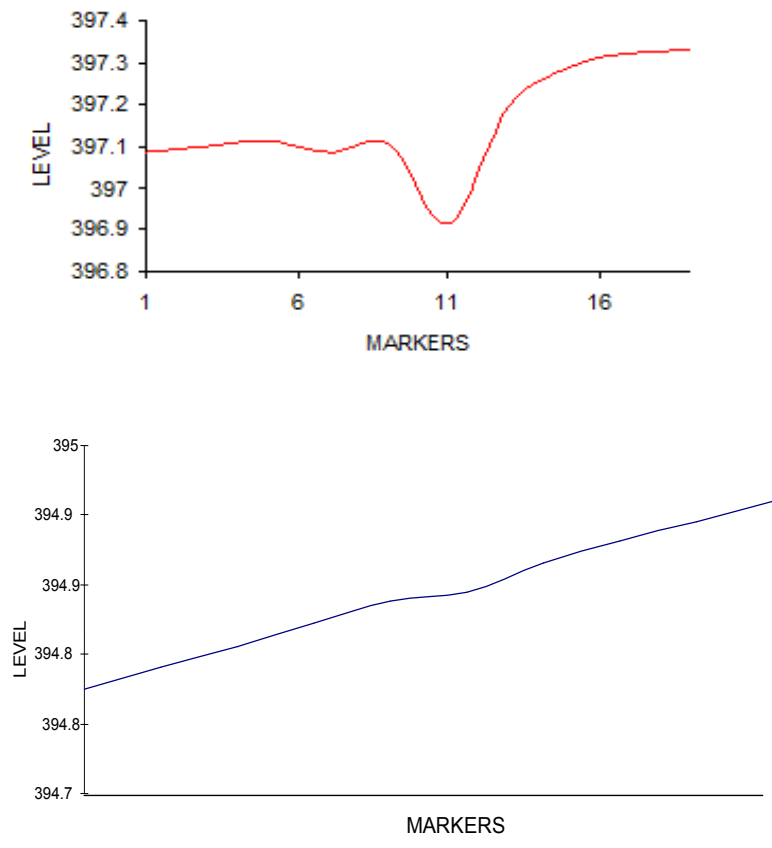

Fig. 2 Profile line of the ceiling (up) and floor (down) gallery's

After conducting and interpreting the periodical measurements by overlaying graphics and by comparison of the levels values, the modifications of the mining works could be assessed. After a series of measurements completed by detailed observations and some measurements of the subterranean mining sites, the stability of these types of cavities could be established and different conclusions concerning the stability of mining works, and consequently the topographical expansion of the influence areas, were drawn. It should be mentioned that for the interpretation of the results concerning the stability of the subterranean mining sites, the eventual caving of the chute for other reasons than the movement of the surrounding rocks, weren't considered.

\section{Conclusion}

The analysis of the topographical measurements conducted for the mining works in the interior of the caving area, indicates that the values of the levels remained the same in the established time frame, and the minor disparities that were shown by different measurements were due to precision degree of the used equipment and the on site practical conditions.

Under these circumstances, the inherent conclusion is that the assessed mining works are stable, without being affected by the modifications of profile in the analyzed time frame, even though their location is in the interior of the caving area. (III degree influence area).

By linking these results with the observations made on the subterranean mining areas of considerable sizes that were a direct result of the excavations of thin veins with a considerable deviation and taking into consideration that the measured mining works are located in the influence are of 
some adits excavated between 1950 -1980, in Sofia and Valea Rosie ores, the final conclusion that can be articulated is that the mining spaces have a satisfying stability for a long period of time.

Taking into consideration the considerable volume of the subterranean mining areas in the mining perimeter of Sasar and their satisfying stability during a long period of time, it can be stated that the subterranean mining area are suitable to support different operations in accordance with the necessities of that area, the shown interest and the consequent financial expenditures.

\section{References}

[1] O. Stefan, G. Bădescu, Need and importance of achieving the mining cadastre from CN REMIN SA Baia Mare, Proceedings of 14th International Conference on Modern Technologies, Quality and Innovation pag: 575-578, (2010), May 20-22; Slanic-Moldova, Romania.

[2] I. E. Keller, S. Bilasco, G. Badescu, L.R. Kollar, Improvement of Decisions by using GIS and Hydraulic Modeling for Sewerage Systems. The Case Study of a Square from Baia Mare City, 2nd International Conference on Environmental and Geological Science and Engineering(EG 09), ROMANIA, (2009), ISSN: 1790-2769, ISBN: 978960-474-119-9, pag.: 261-267

[3] C. Didulescu, A. Savu, A.C. Badea, G. Badea, G. Bădescu, Modeling and Visualization Objects from Point Cloud Data Surveyed With Terrestrial Laser Scanner, Recent Researches in Manufacturing Engineering, Brasov, (2011) ISBN 978-960-474-294-3, pag. 193-198.

[4] N. P. Hreniuc, G. Bădescu, Pollutant Effects of the Natural Bacterial in the Area of Valea Sesei-Rosia Poieni, Advances in Environmental and Geological Science and Engineering, Proceeding of the 2nd International Conference on Environmental and Geological Science and Engineering (EG 09), ISSN 1790-2769 ISBN 978-950-474-119-9 (2009) September 24-26, Brasov, Romania.

[5] P. N. Hreniuc, G. Bădescu, Technologies For Recovering Gold And Very Heavy Metals From Ores And Alluvials, Proceedings of the 14-th
International Modern Technologies, Quality and Innovation, New face of TMCR, (ModTech 2010), pag 311-334 (2010), May 20-22; SlanicMoldova, Romania.

[6] I. E. Keller, V. Dohotar, G. Bădescu, S. Bilasco, Gis In Analysis Of Water Systems For An Area From Baia, Proceedings of the 14-th International Modern Technologies, Quality and Innovation, New face of TMCR, Slanic Moldova, pag 571-574 (2010), May 20-22; SlanicMoldova, Romania.

[7] A. Savu, C. Didulescu, A.C. Badea, G. Badea, G. Bădescu, Measurements in dynamic system of railway tunnels, Recent Researches in Manufacturing Engineering, Brasov, (2011) ISBN 978960-474-294-3, pag. 147-151.

[8] A. Savu, C. Didulescu, A.C. Badea, G. Badea, G. Bădescu, Laser Scanning Airborne Systems - A New Step in Engineering Surveying, Proceedings of the 11th WSEAS International Conference on Sustainability in Science Engineering SSE '09 (2009), May 27-29, Timisoara, Romania.

[9] C. Grecea, Modern Concepts of Urban Cadastre, Proceedings of the 11th WSEAS International Conference on Sustainability in Science Engineering SSE '09, (2009), May 27-29, Timisoara, Romania

[10] P.N. Hreniuc, G. Bădescu, Means for controlling natural bacterial leaching and exploiting dissolved copper, Proceedings of 14th International Conference on Modern Technologies, Quality and Innovation (ModTech 2010), pag: 335-338 (2010), May 20-22; SlanicMoldova, Romania

[11] C. Musat, S.I. Herban. Geoinformation System for Interdisciplinary Planning of Landslides Areas. Proceedings of the 11th WSEAS International Conference on Sustainability in Science Engineering SSE '09, (2009), May 27-29, Timisoara, Romania

[12] D. Onose, A. Savu, A. Negrila, Tracking Behaviour in Time of the Bridge Over the Danube - Black Sea Channel from Cernavoda. Proceedings of the 11th WSEAS International Conference on Sustainability in Science Engineering SSE '09 , (2009), May 27-29, Timisoara, Romania

[13] D. Onose, C. Cosarca, A., A. Negrila, Special Networks used for Tracking Metal Parts of the Sluice. Proceedings of the 11th WSEAS International Conference on Sustainability in Science Engineering SSE '09, , (2009), May 27-29, Timisoara, Romania. 